\title{
CÓDICES DEL MONASTERIO ELNONENSE O DE SAINT-AMAND (entre los siglos IX-XII)
}

\author{
SERAFÍN BODELÓN \\ Universidad de Oviedo \\ sbodelon@uniovi.es
}

\section{RESUMEN}

Hay un Index Minor y un Index Maior de los Manuscritos de la Edad Media, elaborados en el Scriptorium del monasterio Elnonense en el Sacro Imperio Romano Germánico. Fueron escritos en Lengua Latina en la Edad Media. Ofrezco aquí una versión española de ambos documentos.

Palabras Clave: Manuscritos medievales, monasterio Elnonense, Index Minor, Index Mayor.

\section{ABSTRACT}

There is one Index Minor and also one Index Maior of Manuscrits of the Middle Age produced in the Scriptorium of Elnonense monastic center in Sacro Imperio Romano Germanico. They was redacted in Latin in the Middle Age. I offer here a translation to Spanish of these both documents.

Key WoRds: Medieval manuscripts, Elnonensis monastery, Index Minor, Index Maior. 


\section{INDEX MINOR}

El Índice Menor de los Libros Elnonenses, según el Códice Valentin. 33 del siglo XII, fol.2., parece escrito entre los años 1123 y 1136. En él en efecto se realiza la recensión de tres códices, que contienen el libro Sobre la Consolación de la Filosofía, aunque en la época en que se realizó el Index Maior los monjes Elnonenses utilizaban cuatro códices en los cuales se contenía aquella obra. Ya que se cuenta que uno de ellos fue donado por Falcuino I, otro por Hellino, abad de San Teodorico de Reims, parece según ello que el Index Minor fue escrito a continuación, poco después que Falcuino I presentara su renuncia, pero antes de que Hellino fuese promovido a la sede de Reims, es decir, entre los años 1123 y 1136 .

Reverendo Sr. D. Antonio Sander, canónigo de la iglesia catedral de Yprés, F. Ildefonso Goetghebuer, monje Elnonense salud y paz le desea.

Reverendo Señor:

Después de recibir vuestro proyecto, según la carta dirigida a mi Abad, y tras considerar que el proyecto contribuye a mi perfección, al punto le dediqué mi esfuerzo y toda mi diligencia para realizar bien cuanto antes vuestra petición (en la medida en que me lo permitieron las premuras de tiempo y el piadoso cumplimiento del Oficio Divino y la salutífera multitud de prescripciones de los deberes de la Regla).

Así pues escribí de nuevo todo el Catálogo de vetustos Códices manuscritos de nuestra Biblioteca, como usted encargó «sin notas», empezando por el Título, que tú mismo compusiste; y yo por propia iniciativa lo mantendría, si escribiese por mi propia determinación, incluso si no fuere preciso someter mi voluntad a la tuya en asuntos tan preclaros, cultivando el intelecto con sencillez.

Mas ya que al punto capté con creces ese encargo importante por las cosas que luego seguían, añadí brevemente en qué épocas aproximadamente fueron escritos, para no omitir aquellas notas que evidencian la antigüedad de los códices; en cambio no lo anoté, como en otros Catálogos, según la mera apariencia u opinión propia respecto a cada uno de los códices, sino solamente en el caso de aquellos cuya antigüedad consideré cierta, para no hablar con frivolidad de su vetustez o con temeridad. Deduje la certeza por lo encontrado al fin de cualquier códice antiguo (alguno conteniendo obras de S. Jerónimo). Al Catálogo de libros que antiguamente se hallaban en nuestra Biblioteca, se añadieron en algunos libros los nombres de Abades o Hermanos, con cuyo cuidado y previsión aquellos mismos códices fueron escritos; hallado este Catálogo, digo, confeccioné alguna nota mediante esta descripción:

«Este códice fue escrito por cuidado y previsión (v.g.) de Hucbaldo. Pero Hucbaldo floreció hacia el año del Señor 880 ; luego este códice fue escrito hacia el año $880 »$.

Por cuidado y previsión de este Hucbaldo poseemos casi todos los códices más antiguos, especialmente los que se refieren a artes liberales, según manifestará este Catálogo al lector. Así pues, según rectamente dice Trithemio, Hucbaldo monje de S. Amand, francés de nación, fue un varón muy erudito, tanto en las divinas Escrituras, como en asuntos seculares, en Música, en Poética, Filosofía, fecundo en su época y tan insigne por su co- 
nocimiento en las demás artes liberales, que se consideraba igual a los antiguos filósofos. Su tío Milón, monje del cenobio de S. Amand, varón doctísimo en cualquier campo, orador, poeta y músico insigne y no menos venerable por la honestidad de sus costumbres que por el conocimiento de las Escrituras, fue tenido en gran consideración por parte de Carlos el Calvo, difundió incluso hasta remotas regiones las ideas de su saber. Por lo cual el Emperador Carlos el Calvo, (quien a su vez había morado cierto tiempo en este mismo monasterio) confió a estos dos monjes nuestros a sus propios hijos gemelos, Drogón y Pepino, para que se ilustraran en las letras, juntamente con su hermano Carlomán (después también Abad Elnonense).

En aquel tiempo también otros muchos hijos de Duques y de Condes eran educados aquí en los estudios de las artes liberales. Por causa de ello se lee que el propio Carlos concedió a este mismo cenobio diversos bienes y privilegios. Así pues resultó que incluso hasta el día de hoy han permanecido entre nosotros tan antiguos y preclaros libros. No he anotado nada de los demás, aunque quizás algunos son muy vetustos cuando no hallé nada cierto. Sólo digo aquí esto, que hay poquísimos o casi ningún manuscrito de nuestra Biblioteca, que tenga menos de trescientos o más años. Cierto Reverendo Señor vuestro había pedido que se le copiara un texto griego, pero con letras griegas, junto a un Salterio de Jerónimo en cuatro partes. Pero pareció bien al Reverendo Señor mi Abad, que no se copiase de otro modo a como está en los manuscritos antiguos; ya que el Salterio griego está escrito en ese códice en letras latinas, no consideramos hacer nada, más allá de vuestra intención, si aquí se escribe todo con las mismas letras que constan escritas.

Esto en fin he resuelto siempre en todas las circunstancias, de suerte que no cambio nada, ni en los títulos de los Tratados y Obras, ni en los Autores de aquellas obras que hallé en los mismos Códices. Por lo tanto si en cualquier momento los títulos parecían demasiado oscuros, yo he intentado tornarlos más claros, pero sin cambiar o alterar palabras, sino construyendo con términos más simples y breves un término nuevo, adecuado al antiguo. No sustituí nada, a no ser tras larga y ansiosa investigación, según los diversos libros, tanto impresos como manuscritos. Añadí también aquí un lugar para los Índices, junto a cada una de las páginas, así como una palabra que separa los libros según sus diversas características. Como por ejemplo, bajo el término S. AGUSTÍN, siguen las Obras de S. Agustín, y así sucesivamente. Así pues emprendí todas estas operaciones, según mi parecer, para mejor merecer la gracia y gloria divina; y a la vez para mejor satisfacer una petición, tan generosa y conveniente como la tuya.

Otras muchas y más importantes cosas gustosamente emprendería en cualquier circunstancia, con brillante sacrificio por mi parte, como su ilustre persona merece. Rogaré entretanto que la Bondad Divina te proporcione larga vida y salud, para llevar a cabo la obra que se ha emprendido, y tras esta vida de esfuerzos, una nueva vida eterna. A su servicio. El humilde siervo en Cristo. F. Ildefonso Goetghebuer.

Comienza el Catálogo de Viejos Libros Manuscritos del Monasterio Elnonense

La letra y el Número significa la nota del mismo libro: pues antiguamente las Escrituras no ponían a los libros otras notas más que las de la letra misma, o mejor a los vo- 
lúmenes correspondientes; ni escribían Títulos en todos, o bien sobrescritos en los volúmenes de los Tratados allí contenidos, sino que los autores posteriores se tuvieron que esforzar para añadir, revolviendo con minuciosidad en cada uno de los volúmenes todos los libros de la Biblioteca completa, cuantos títulos descubrían que faltaban en los mismos. Y yo, teniendo en cuenta esto al pie de la letra, confiado en el auxilio divino, puse en orden esto lo más depurada y brillantemente que pude, para alabanza y gloria de Dios, y según mis posibilidades intenté copiarlo de nuevo para provecho y salud de mis Hermanos, describiendo a continuación en este opúsculo cuanto se contiene en cada uno de nuestros manuscritos. Así en lo sucesivo será muy fácil para cualquiera tener a mano al punto sin ninguna dificultad cualquier códice manuscrito de nuestra Biblioteca.

\section{EMPIEZAN los Códices MANUSCRITOS}

1. Sagrada BIBLIA en dos volúmenes muy magníficos, escritos muy elegantemente, decorados con figuras de arte que maravilla cada uno de ellos, tanto del Nuevo como del Viejo Testamento, estructurados con cubiertas de envoltura vegetal muy insigne. Se escribió en tiempos del Reverendísimo D. Gregorio Egmond, obispo de Mastricht, Abad Comendatario hacia el año del Señor de 1540.

2. BIBLIA en nueve volúmenes grandes muy antiguos, en los que, aunque en los mismos los libros de la Escritura se hallan más frecuentemente, en cada uno de ellos sin embargo se encuentran algunos que están en distinto orden, o bien no están. De tal modo que en estos nueve volúmenes no se contiene nada más que la Biblia, con algunos libros repetidos a veces con más o menos frecuencia. Y en todos ellos, que contienen los Evangelios de los cuatro Evangelistas, preceden a los mismos Evangelios los Cánones de S. Jerónimo.

3. LECCIONARIO antiguo en folio.

4. MISAL en folio y dos tomos, uno para la estación Invernal y otro para la Estival.

5, BEDA. Comentario sobre Marco (Tulio Cicerón).

6. BEDA. Exposición sobre las Parábolas. Salomón.

7. BEDA. El De temporibus publicado por vez primera. El De Natura Rerum, De Numero. Sobre las seis edades del mundo. Crónicas varias desde el año 975, y desde el año 1770 de la fundación del mundo. Catálogo de los abades del cenobio Elnonense, en el cual se describen ciertos hechos de aquellos.

8. BEDA. Liber de natura rerum. Tabla de S. Jerónimo para saber la luna de cada día. Martirologio de Eusebio. Sobre las seis edades de este mundo. Los nombres de los obispos de Verdún y nombres de los obispos de Tournai o Noniomagenses. Finalmente nombres de los obispos de la Iglesia de Tonares y de Laón.

9. HILARIO. De Trinitate en doce libros, con varios opúsculos contra todos los herejes y contra el arriano Auxencio. Este códice fue escrito en el año 990.

10. GREGORIO NACIANZENO. Los ocho Libros del obispo:

\section{Liber Apologeticus.}

2. De Epifania o del Nacimiento del Señor.

3. De Luminibus siue de Epiphaniis. 
4. De Pentecostés, o sobre el Concilio sobre el Espíritu Santo, celebrado en la Iglesia de Constantinopla.

5. Regreso desde el campo.

6. Sobre las palabras de Jeremías en presencia del emperador, ante el cual intercede por alguien que corría peligro.

7. Sobre la reconciliación del monje.

8. Sobre la devastación del granizo mientras el obispo guardaba silencio. Los Tres libros a Mónimo del obispo Fulgencio. Las Objeciones de Trasamundo, rey arriano de los vándalos contra la fe católica y contra Las Responsiones de Fulgencio. Los tres libros de Fulgencio contra el mismo Trasamundo: El 1. ${ }^{\circ}$ sobre el misterio del mediador. El 2. ${ }^{\circ}$ sobre la inmensidad de la divinidad del hijo de Dios. El 3. ${ }^{\circ}$ sobre el Sacramento de la Pasión Dominical. Del mismo Fulgencio las siete Epístolas a los siervos y siervas de Cristo.

11. GREGORIO NACIANCENO. De nuevo los ocho libros antes citados.

12. FULGENCIO. Los cuatro Libros a Mónimo. De nuevo las Objeciones al rey de África Trasamundo contra la fe católica y las Responsiones de Fulgencio. El 1. ${ }^{\circ}$ Del misterio del mediador. El 2. ${ }^{\circ}$ De la inmensidad de la divinidad del hijo de Dios. El 3. ${ }^{\circ}$ Del Sacramento de la Pasión Dominical y las siete Epístolas del mismo: $1 .^{a}$ De la deuda con-

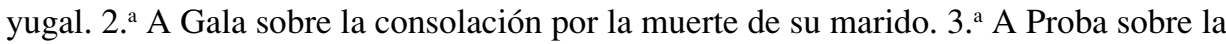
Virginidad y la Humildad. 4. ${ }^{a}$ A Proba sobre la oración a Dios. 5. Al Abad Eugipio sobre la caridad y su afecto. 6. ${ }^{\mathrm{a}} \mathrm{Al}$ Senador Teodoro sobre la conversión del mundo. 7. ${ }^{\mathrm{a}} \mathrm{A}$ Venancio sobre la correcta Penitencia y la recompensa futura.

Queda una carta de GATARO, abad Elnonense, redactada en el año 1123, que Falcuino I firmó en segundo lugar; sin embargo consta que Helino fue hecho abad de S. Teodorico hacia el año 1136. El primer editor fue J. MUNGEANT, quien falsamente pensó que habían sido redactados en este Ïndex todo tipo de libros, a pesar de que sólo se hace mención de los libros que se refieren a la enseñanza:

I. PLATÓN. El Timeo con la exposición de Calcidio al mismo.

II. BOECIO. Sobre la Trinidad.

III. BOECIO. Comentario sobre los Topica de Cicerón con las interpretaciones de Apuleyo y con los libros del mismo Boecio Topica, Differentiae, De diuisione sobre la especulación común del conocimiento retórico, sobre la distinción de las Figuras Retóricas, sobre los muchos puntos de la predicación, cómo y de dónde pueden sacarse los puntos de los razonamientos, sobre la introducción a los Silogismos Categóricos, sobre los silogismos hipotéticos, en un sólo volumen.

IV. BOECIO. Los dos libros de Música.

V. BOECIO. Tres libros sobre la Consolación de la Filosofía.

VI. BOECIO. Aritmética.

VII. BOECIO. Los Topica de Cicerón con comentario de Boecio. Igualmente el comentario de Boecio sobre el mismo volumen primero.

VIII. ARISTÓTELES. Los Periermeneiae de Aristóteles y el comentario de Boecio a los mismos junto con los comentarios a las Isagogae de PORFIRIO.

IX. PORFIRIO. Siguen a los mismos las Isagogae de PORFIRIO junto con las Interpretationes de APULEYO. 
X. PORFIRIO. Las Isagogae de Porfirio y las Categorías de ARISTÓTELES traducidas por Agustín, junto con las Interpretationes de APULEYO, y con el comentario de Boecio a las Periermeneiae de ARISTÓTELES.

XI. CICERÓN. Rhetorica. De Inuentione.

XII. Rhetorica Ad Herennium.

XIII VICTORINO. De Rhetorica.

XIV. MARCIANO CAPELA. Los dos Libros de Marciano Capela.

XV. VEGECIO RENATO. De re militari.

XVI. NONIO MARCELO. Glosas de Nonio Marcelo al Peripatético según el orden del alfabeto con los libros de CLAUDIANO, y con preguntas y respuestas en sajón y en francés sobre DONATO y con FLODEGARIO Sobre los barbarismos.

XVII. MACROBIO. Sobre el Sueño de Escipión.

XVIII. MARIO PLOTIO. Sobre Métrica con los Proverbios de SÉNECA y con el Apocolocintosis del mismo o burla sobre la muerte de Claudio.

XIX. MARIO VICTORINO. Sobre la Gramática y la Variedad de Metros con versos de Virgilio, con las Concordancias tomadas del Antiguo y Nuevo Testamento.

XX. PRISCIANO. Las dos obras mayores, uno de ellas el Ars Euthicii.

XXI. PRISCIANO. Los doce primeros versos de los libros de la Eneida con glosas de LACTANCIO sobre La Tebaida de ESTACIO.

XXII. PRISCIANO. Sobre las Figuras de los números. Sobre los Metros de Terencio. El libro del Arte Arquitectónica. La Geometría. Diálogo de Albino y Carolo sobre Dialéctica y Retórica. La Música de Otgero y Enquiriadis.

XXIII. PRISCIANO. Sobre Medicina.

XXIV. HIPÓCRATES. Aforismos de Hipócrates junto con comentario sobre los mismos.

XXV. ALBINO. Dos cláusulas de Albino sobre Prisciano el Mayor.

XXVI. PRUDENCIO. Psicomaquia junto con ARATOR.

XXVII. EUGRAFIO. Comentario sobre Terencio, junto con las Categorías de ARISTÓTELES traducidas por Agustín y a la vez los milagros de San Esteban.

XXVIII. VIRGILIO. Dos obras. SERVIO Sobre Virgilio.

XXIX. LUCANO.

XXX. SALUSTIO. TERENCIO.

XXXI. Un Glosario.

\section{INDEX MAIOR}

Según el Códice de París 1850, pergamino del siglo XII, fol.190, v﹎o-202. Fue escrito el Index Mayor entre los años 1150 y 1168 . Entre los libros con los que uno de los responsables de la Biblioteca la adornó, había dos volúmenes, "de letra minúscula del venerable Abad Hugo II", en los que se contenía el Antiguo y el Nuevo Testamento. Consta que éste estuvo al frente de Elnone desde el año 1150 hasta el año 1158. Además en el inicio del Códice 257, (ahora Parisino 3853) se describe una serie de Emperadores Germánicos y Pontífices Romanos, que finaliza con estas palabras: "Federico I, en su época se escribió este libro". De lo cual se deduce que el códice fue escrito entre los años 1154 
y 1159. Lo mismo se ha de decir sobre el Códice Parisino 5129, en el que se lee una sucesión de Pontífices Romanos y de reyes de la ciudad de Jerusalén (fol. 88 vo y 66 vo ), que también remite a aquella época. Así pues no cabe ninguna duda de que el Index Maior fue escrito en la época en que Hugo II gobernaba el Cenobio Elnonense, y en aquella de un monje de nombre incierto, que sobrevivió a Hugo durante algún tiempo.

\section{ANotación a los Libros de La Biblioteca de SAINT-AMAND}

Hemos anotado debajo los nombres de los Hermanos, con cuyo cuidado y esfuerzo se escribieron los libros, de los que pudimos tener noticia.

I. Un gran volumen en el que se contiene todo el Antiguo y Nuevo Testamento. Se dice que la reina Susana entregó este libro a nuestra iglesia, entre otras cosas que le concedió. Ella decoró el oratorio en medio de la iglesia de Saint Amand, donde el señor Hucbaldo había depositado las reliquias del Santo mártir Cirico; y lo ornó con mármol de Paros, oro y plata con suntuosa y hermosísima factura; después un incendio lo devastó lo mismo que la iglesia.

II. Dos grandes volúmenes que contienen separadamente el Antiguo y el Nuevo Testamento, excepto el Evangelio y el Salterio. ALARDUS.

III. Un volumen muy antiguo en el que se contienen los Hechos de los Apóstoles, Epístolas, Cánones, Apocalipsis, Libros de Salomón, el Libro de Sabiduría.

IV. Los doce Profetas en un pequeño volumen. AMULRICVUS.

V. Job en un volumen pequeño. AMULRICUS.

VI. El Salterio en tres libros viejos: dos incluso mejorados según Jerónimo; el tercero con acompañamiento de notas.

VII. Cinco libros antiguos según las mismas notas explican.

VIII. Los Salmos con glosario de Alardo, Guniardo, Floricio, Ercembaldo, junto con el Himnario y la Pasión del Señor según los cuatro Evangelistas, con los Himnos de Oberto, con los Himnos de Gualterio, con los Himnos de Hugo, con los Himnos de Gaufrido.

IX. Salterio de Gunterio, junto con los Himnos de Bové.

$X$. Salterio de Jordan junto con los Himnos de su hermano.

XI. Salterio de Gilberto glosado.

XII. Glosas del maestro Gilberto sobre los Salmos. Maestro GILBERTO, monje nuestro, antes canónigo de San Andrés.

XIII. Glosas del maestro OFFRIDO sobre algunos versos de los Salmos.

XIV. El Cantar de los Cantares glosado. OFFRIDO.

$\mathrm{XV}$. Mateo glosado. OFFRIDO.

XVI. Juan glosado. OFFRIDO.

XVII. Apocalipsis glosado. OFFRIDO.

XVIII. Epístolas de Pablo. OFFRIDO.

XIX. El Cantar de los Cantares glosado. HELINO, nuestro prior.

XX. El Cantar de los Cantares glosado, junto con el Apocalipsis.

XXI. El Apocalipsis adornado, con el libro de los Sermones de Agustín.

XXII. Tres textos de los Evangelios. 
XXIII. Mateo glosado. GUALTERIO, nuestro prior, después abad de S. Martín.

XXIV. Epístolas de Pablo glosadas. GUALTERIO.

XXV. Dos Homiliarios. GUALTERIO, el prior.

XXVI. Josefo. Cinco libros.

XXVII. Historia de Clemente.

XXVIII. Historia de Egesipo.

XXIX. Orosio. Historia contra los paganos.

XXX. Historia rei perditae. GUALTERIO I nuestro en otro tiempo.

XXXI. Historia Eclesiástica.

XXXII. Historia de Jordanes: Sobre el origen y hechos de los Romanos. Libros de Euquerio: Sobre la erudición de las divinas Escrituras.

XXXIII. Historia de Eutropio. Sobre los Hechos de los Romanos y los asuntos bélicos y civiles. HUCBALDO, monje insigne y músico loable, que compuso sobre muchos cantos sacros, quien también trajo a nuestra iglesia las reliquias de San Cirico mártir.

XXXIV. Historia de Alejandro Magno con las gestas de Apolonio. GUALTERIO.

XXXV. Cosmografía del filósofo Etico.

XXXVI. Tres volúmenes de Cánones.

XXXVII. Selección de Leyes.

XXXVIII. Libro sobre Sagradas Órdenes.

XXXIX. Dionisio Aeropagita: La Jerarquía.

XL. Tertuliano: El Liber Apologeticus.

XLI. Lactancio: Sobre la verdadera y la falsa religión.

XLII. Lactancio: De orificio corporis humani, con la Música de Bernardo.

XLIII. Casiodoro: Sobre el alma.

XLIV. Casiodoro: Sobre las artes y disciplinas de los estudios profanos.

XLV. Orígenes: Sobre la singularidad de los clérigos y el sacrificio de la expiación, junto con Plinio: Sobre Medicina; y también vez decretos de ciertos obispos.

XLVI. Fulgencio: Libros a Mónimo sobre el misterio del mediador, Sobre la inmensidad del hijo de Dios, Sobre el Sacramento de la Pasión Dominical, junto con seis Epístolas del mismo en un solo volumen.

XLVII. Gregorio Nacianceno: Liber Apologeticus, Sobre la Epifanía o del Nacimiento del Señor, Sobre las luces o segunda Epifanía, Sobre Pentecostés, El regreso del campo, Sobre el profeta Jeremías, Sobre la reconciliación del monje, Sobre la devastación del granizo, en un solo volumen.

XLVIII. Jerónimo: Sobre Jeremías.

XLIX. Jerónimo: Sobre Ezequiel. GUALTERIO.

L. Jerónimo: Sobre Isaías en dos volúmenes.

LI. Jerónimo: Sobre Daniel. El libro De Viris Illustribus, con la exposición de Beda sobre siete Epístolas canónicas.

LII. Jerónimo: Sobre los doce Profetas en dos volúmenes. GUALTERIO.

LIII. Jerónimo: Sobre Mateo, con los libros Contra Joviniano.

LIV. Jerónimo: Sobre las Epístolas de Pablo a los Gálatas, a Tito, a Filemón.

LV. Jerónimo: Sobre la Epístola a los Efesios, a quien fueron enviadas Pasiones y Vidas de ciertos Santos. 
LVI. Jerónimo: Sobre el Cantar de los Cantares, con frases de los libros de Agustín Sobre la Trinidad.

LVII. Jerónimo: Contra Helvidio sobre la virginidad de Santa María con algunos opúsculos del mismo. GUALTERIO.

LVIII. Jerónimo: Crónica. HUCBALDO.

LIX. Jerónimo: Epístolas varias, Breviario menor sobre los Salmos, Diálogo de Ático y Cristóbulo sobre los nombres. Agustín: Sobre el origen del alma, Sobre el pensamiento del Apóstol Santiago. Crónica del obispo Isidoro. Liber Apologeticus de Orosio, en un sólo volumen. HUCBALDO.

LX. Ambrosio: Epístola a Siagro, con el libro de Juan Crisóstomo Sobre la ofensa.

LXI. Ambrosio: Florilegio de libros de Ambrosio sobre El Cantar de los Cantares. Igualmente de los libros de Gregorio sobre el mismo tema. HELLINO, abad de S. Teodorico.

LXII. Agustín: Sobre la Trinidad. HUCBALDO.

LXIII. Agustín: Sobre el texto del Génesis. FULQUINO, el prior.

LXIV. Agustín: Sobre la Epístola de Juan.

LXV. Agustín: Liber Enchiridion.

LXVI: Agustín: Liber ad comitem.

LXVII. Agustín: Sobre la naturaleza y el origen del alma. HUCBALDO.

LXVIII. Agustín: A Renato sobre la grandeza del alma. Sobre la naturaleza y el origen del alma misma. Epístola a Pedro. Dos libros a Vicentio Victor sobre la naturaleza y origen del alma. HUCBALDO.

LXIX. Agustín: Contra Cresconio, con la Epístola del Papa Nicolás al Emperador Miguel, y con la Vida del abad Launomaro.

LXX. Agustín: Sobre la doctrina cristiana y sobre el cuidado que ha de tenerse sobre los muertos. GUALTERIO.

LXXI. Agustín: Las Confesiones, con los libros sobre El bien conyugal, Sobre la fe verdadera, Sobre los Herejes, Sobre el trabajo de los monjes, y los Sermones sobre la Penitencia. BORO II, abad.

LXXII. Agustín: Sobre el Salterio, en tres volúmenes. FLORICO.

LXXIII. Agustín: Sobre Juan en dos volúmenes; en el segundo se encuentra el libro sobre el Sermón del Señor en la Montaña. GUNTERO, el prior y GUALTERO.

LXXIV. Agustín: Disputa de Agustín y Arrio, con el libro de Ambrosio contra los Arrianos y con los Soliloquios de Agustín.

LXXV. Agustín: A Valentino sobre el libre arbitrio y la gracia de Dios. Su disputa contra Feliciano con algunas costumbres de la Iglesia Romana ya asumidas.

LXXVI. Agustín: Contra Parmeniano, con tres Epístolas. GUALTERO, abad de S. Martín.

LXXVII. Agustín: Sermones sobre la Pascua, con algunos opúsculos. Homilías de Eusebio de Cesarea enviadas sobre la Pascua.

LXXVIII. Agustín: Quejas sobre Eptático, con los Sermones sobre la Asunción de Santa María.

LXXIX. Agustín: Musicae duae.

LXXX. Agustín: Las Categorías. 
LXXXI. Agustín: El libro de Eugipio, expurgado según los libros de Agustín. LOTARIO, que elevó desde la tierra a S. Amando.

LXXXII. Agustín: Sobre la Penitencia. Sobre las costumbres de la Iglesia Católica.

LXXXIII. Gregorio: Dos Pastorales.

LXXXIV. Gregorio: Sobre Ezequiel, con las Cartas de Agustín a Jerónimo y de Jerónimo a Agustín.

LXXXV: Gregorio: Dos volúmenes de los Morales, es decir, la parte quinta y sexta. HUCBALDO.

LXXXVI: Gregorio: El Diálogo.

LXXXVII: Gregorio: Paterio expurgado según los libros de Gregorio.

LXXXVIII: Gregorio: Selección de los libros de Gregorio sobre algunos versos del Salterio y sobre todos los Profetas. HELINO, abad de S. Teodorico.

LXXXIX. Isidoro: Soliloquios, con la Pasión de San Sebastián, y con las Sentencias de Próspero, según los libros revisados de Agustín.

$\mathrm{XC}$. Isidoro: Etimologías en dos libros.

XCI. Isidoro: Sobre algunas cuestiones de Eptático. GILBERTO I.

XCII. Isidoro: De temporibus, con la Epístola enviada al Papa Nicolás.

XCIII. Isidoro: De Retórica y Dialéctica, con la disputa de Albino y Carolo sobre la Dialéctica y la Retórica, y con otros opúsculos. HUCBALDO.

XCIV. Isidoro: La disputa de Albino y Carolo.

XCV. Albino: Sobre el Evangelio de Juan.

XCVI. Albino: A Carlos sobre la fe de la Santa Trinidad. HUCBALDO.

XCVII. Albino: Antología de Prisciano el Mayor. GILBERTO I.

XCVIII. Beda: Sobre las parábolas de Salomón.

XCIX. Beda: Sobre Marcos, con la Vida de S. Gil.

C. Beda: Tres libros Sobre la Naturaleza de las cosas. De temporibus.

CI. Beda: Ortografía.

CII. Beda: Sobre el arte Métrica, con la Vida de S. Amando, escrita por Milón en verso.

CIII. Milón: De Sobrietate.

CIV. Pascasio: Sobre el cuerpo y la sangre del Señor.

CV. Amalario: Sobre los oficios divinos.

CVI. Libro de las Sentencias de muchos Doctores sobre el Génesis.

CVII. Rábano: Sobre el Génesis, con cuestiones sobre el Génesis de varios libros escogidos de muchos doctores.

CVIII. Rábano: Del Cómputo.

CIX. Angelomo: Sobre los Libros de los Reyes.

CX. Haimo: Sobre el Apocalipsis.

CXI. Próspero: Sobre la vida activa y la contemplativa. Epigramas selectos de los libros de Agustín.

CXII. Próspero: Epigramas de Próspero.

CXIII. Próspero: Próspero en verso, a partir de obras diversas.

CXIV. Prudencio: Himnos, junto con el Peristephanon.

CXV. Prudencio: Contra Símaco, opúsculos del Viejo y Nuevo Testamento. Contra los Patripasianos, Contra los Unionitas, Contra los Omusionitas, Contra los Judíos, Sobre 
la naturaleza del alma, Contra los Fantasmáticos, El Amartigenia Liber, en un solo volumen.

CXVI. Prudencio: Glosas sobre los mismos opúsculos, junto con edición de Sobre las Partes de la Oración de Donato, junto con la Institutio de Prisciano.

CXVII. Prudencio: Tres libros de Psicomaquia, junto con los Hechos de los Apóstoles de Arator.

CXVIII. Arator: el mismo título anterior.

CXIX. Arator: Glosas sobre Arator, con las Categorías de Agustín, sobre el barbarismo admitido y las partes de la oración en segunda edición de Donato.

CXX. Sedulio: El Paschale Carmen con glosas sobre el mismo.

CXXI. Juvenco: El Evangelio de Lucas en verso.

CXXII. Fortunato: Opúsculos diversos en verso, con su tratado sobre la Oración gramatical.

CXXIII. Martirologio de Jerónimo y de Beda, junto con la Regla de S. Benito.

CXXIV. Smaragdo: Sobre la Regla de S. Benito.

CXXV. Otro libro sobre la misma Regla, sacado de los libros de los Padres.

CXXVI. Corona de monjas, con la Vida de Santa María Egipcíaca.

CXXVII. Regla de los Santos Monjes, tomada de los libros de los Padres. HUCBALDO.

CXXVIII. Libro sobre los ocho vicios principales, y Sobre la vida activa y contemplativa, y Sobre la Penitencia.

CXXIX. Dos libros Penitenciales.

CXXX. Julián: Liber Pronosticorum del obispo Julián,

CXXXI. Efrén: Sermón de Efrén, con el Testamento de San Remigio, y con la Disputa del arzobispo Hincdemaro contra el monje Todescalco.

CXXXII. Sermones de Jonás de Orleáns.

CXXXIII. Dos libros sobre los Evangelios.

CXXXIV. Anselmo: Libros de Anselmo, obispo de Canterbury: Monologion. Proslogion. Sobre la Encarnación del Verbo. El libro ¿Por qué Dios se hizo hombre?. Del pecado original y sobre el concepto de virginidad. Sobre el descenso del Espíritu Santo. Sobre la verdad. Sobre el libre arbitrio. Sobre la caída del diablo, en un solo volumen.

CXXXV. Colationes de los Padres en dos volúmenes; en el primero se contienen el De reparatione Lapsi de Juan Crisóstomo.

CXXXVI. Paradisus sobre la conversión de los Santos Padres, con la doctrina de San Basilio, junto con otros opúsculos.

CXXXVII. Vidas de los Padres, junto con el De Officiis de Isidoro.

CXXXVIII. Pasiones de los Apóstoles y Vidas de los Santos Marcial, Remigio, el abad Mauro, Basilio, junto con la pasión de San Blas.

CXXXIX. Pasión de Santa Catalina.

CXL. Dos vidas de San Martín.

CXLI. Dos Vidas de San Amando, junto con una pasión de San Salvio y la vida de San Barón.

CXLII. Vida de San Gregorio, y previamente con la pasión de Santa Martina.

CXLIII. Vida de San Eligio, junto con la vida de San Germán de Autún.

CXLIV. Vida de San Furseo con su Traslatio a Santa María Magdalena.

CXLV. Vida de San Juan el Limosnero. 
CXLVI. Pasiones y Vidas de muchos Santos en ocho volúmenes; éstos son los primeros de los cuales: Pasión de S. Vicente, pasión de S. Nicasio, pasión de S. Ignacio, pasión de los santos Cirico y Julita, pasión de Santa Juliana virgen, una parte de la Vida de S. Martín. La Traslatio de S. Benito. Sermón sobre el nacimiento de S. Remigio.

CXLVII. Odón, obispo de Cambrai: Sobre el Canon. La disputa con el judío. Libros sobre el pecado original y sobre la blasfemia del Espíritu Santo, con versos de Hildeberto sobre el misterio de la Misa, y con versos de Pedro Pictor sobre el Sacramento del cuerpo dominical.

CXLVIII. Hildeberto: Hildeberto, obispos de Le Mans. La Vida de St. ${ }^{a}$ María Egipcíaca, con el libro que se llama Las delicias del clero; y con otros muchos opúsculos. Libro dedicado a Marbodo de Rennes sobre las Pasiones de algunos Santos. GILBERTO.

CXLIX. El Lucidarium, al que siguen muchos pensamientos de libros selectos de doctores, tras intercalar el De oratione dominica de Cipriano. GILBERTO.

CL. Muchos Proverbios seleccionados de libros profanos. Y Sentencias escogidas de los libros de muchos católicos, junto con el libro de Séneca titulado De copia uerborum. GILBERTO.

CLI. Libro de los Privilegios de la iglesia de Saint Amand.

CLII. Libro de las Oraciones.

CLIII. Glosario.

CLIV. Hilperico: Dos libros de Hilperico, Sobre el curso del sol y de la luna.

CLV. Gerlando: La Tabla de Gerlando sobre lo mismo con la explicación.

CLVI. Gerlando: Las Reglas de Gerlando para el cálculo de dicha Tabla.

CLVII. Las Reglas del cálculo de similar modo.

CLVIII. Tres Tablillas con las características de su técnica.

CLIX. Igualmente las Reglas del ábaco y la competición del cálculo.

CLX. Tabla de competición del cálculo, con figuras de números de la misma técnica.

CLXI. Esfera de las quince constelaciones.

CLXII. Tres mapas.

CLXIII. Boecio: Sobre la Trinidad con glosas sobre el mismo tema.

CLXIV. Boecio: Los cuatro libros sobre la Consolación de la Filosofía. HELLINO, abad uno. FULQUINO, prior, otro.

CLXV. Boecio. Música, en dos libros.

CLXVI. Boecio. Aritmética, en dos libros.

CLXVII. Boecio. Los Tópica de Cicerón con comentarios de Boecio.

CLXVIII. Boecio: Dos volúmenes conteniendo el anterior comentario en cada uno de ellos; en uno de ellos están los Periermeneiae de Apuleyo, con el libro de Boecio sobre los Tópica, las Diferencias, el De diuisione, Sobre la especulación general del conocimiento retórico, Sobre la distinción de las Figuras Retóricas, Sobre la predicación en cualquier circunstancia, Cómo y de dónde puede tomarse el contenido de los temas, Sobre la exposición de los silogismos categóricos, Sobre los silogismos hipotéticos.

CLXIX. Porfirio: Las Isagogae, con el inicio de los Comentarios de Boecio a Fabio respecto a ellas.

CLXX. Porfirio: De nuevo las Isagogae de Porfirio y las Categorías de Aristóteles, con las Periermeneiae de Apuleyo, así como el Comentario de Boecio a las Periermeneiae de Aristóteles. 
CLXXI. Aristóteles: Periermeneiae de Aristóteles y el Comentario de Boecio a las mismas con los Comentarios de Porfirio a las mismas, siguiendo luego las mismas Isagogae, con las Periermerneiae de Apuleyo.

CLXXII. Aristóteles: Glosas sobre las Isagogae de Porfirio, con glosas sobre las Categorías de Aristóteles y sobre sus Periermeneiae, y a la vez el libro que se llama Las delicias del clero.

CLXXIII. Cicerón: Sobre la Amistad, Sobre la Vejez, Sobre la Paradoxis. ROBERTRO.

CLXXIV. Cicerón: La Retórica de Cicerón, el De Inventione. FULCO.

CLXXV. Cicerón. Glosas sobre la Retórica. FULCO.

CLXXVI. Cicerón: Retórica. A Herennio. FULCO.

CLXXVII. Retórica de Consulto.

CLXXVIII. Platón: El Timeo, con la explicación de Calcidio de la misma obra. HUCBALDO.

CLXXIX. Marciano Capela: Dos libros. HUCBALDO, uno. FULQUINO el prior, otro.

CLXXX. Virgilio: Dos ejemplares.

CLXXXI. Servio: Sobre Virgilio.

CLXXXII. Lucano.

CLXXXIII. Salustio.

CLXXXIV. Horacio.

CLXXXV. Horacio: Arte Poética.

CLXXXVI. Glosas al Arte Poética.

CLXXXVII. Terencio, junto con Homero, De excidio Troiae.

CLXXXVIII. Eugrafio: Sobre Terencio, junto con las Categorías de Agustín y otros opúsculos.

CLXXXIX. Mario Victorino: De Gramática, De la variedad de los metros, con citas de versos de Virgilio y concordancias del Viejo y Nuevo Testamento. HUCBALDO.

CXC. Mario Plotio: Sobre Métrica, con Proverbios de Séneca, y con la Sátira del mismo sobre la muerte de Claudio.

CXCI. Macrobio: Sobre el sueño de Escipión, precedido del mismo sueño.

CXCII. Persio. FULCO.

CXCIII. Juvenal.

CXCIV. Glosas sobre Juvenal.

CXCV. Donato: Segunda edición del Sobre las Partes de la Oración, y la Institutio del mismo Prisciano, con la explicación de Remigio sobre el barbarismo.

CXCVI. Nonio Marcelo: De compendiosa doctrina, junto con el Sobre la propiedad de las palabras. Claudiano: De Anima. Diálogo en sajón y francés sobre Donato. Flodegario: Sobre el barbarismo. Todo en un volumen.

CXCVII. Prisciano: Dos volúmenes grandes, en uno de los cuales está el Ars de Eutiquio. $H U C B A L D O$.

CXCVIII. Prisciano: Soluciones sobre estas cuestiones sobre las que duda Cosroes, rey de los Persas.

CIC. Prisciano: Sobre los doce primeros versos de la Eneida, con las Glosas de Lactancio sobre la Tebaida de Estacio. 
CC. Prisciano: De nuevo sobre los mismos versos, tras intercalar antes el Pauper apis de Quintiliano, con las Cartas de Alejandro a Díndimo y de éste a Alejandro.

CCI. Prisciano: Sobre las figuras de los números. Sobre los Metros de Terencio, Sobre ejercicios, Libro del arte Arquitectónica y Geometría, con el Diálogo de Albino y Carolo sobre la Dialéctica, y con la Música de Otgero y el Enchiriadis.

CCII. Prisciano: Sobre el Nombre, el Pronombre, el Verbo y el Participio con explicaciones, intercalando algunas Notas sobre Terencio.

CCIII. Prisciano: Sobre Medicina.

CCIV. Prisciano: Reglas selectas.

CCV. Prisciano: Glosas sobre Prisciano sobre las construcciones.

CCVI. Hipócrates: Aforismos de Hipócrates con comentario a los mismos, es decir, el conocimiento por el que se generan todas las enfermedades. Libro antiquísimo.

CCVII. Oxigario: Libro de la salmuera con vinagre.

CCVIII. Hipócrates: Los Antídotos. Comentario sobre los Aforismos de Hipócrates. Galeno: A Paterno, Sobre las propiedades de las hierbas, los aromas, las rocas y los seres vivos. Libro sobre el pulso y la orina. Cirugía con imágenes y dibujos en un volumen.

CCIX. Dioscórides: Sobre las propiedades de las hierbas. Libro sobre la orina dedicado a Constantino, monje de Montecasino, traducido del árabe al latín, en un volumen.

CCX. Galeno: Sobre los dolores. Speculum medicinale. Los Antídotos. A Paterno sobre las propiedades de las hierbas, los aromas, las rocas y los seres vivos, en un volumen.

CCXI. Constantino: Libro de las fiebres de Constantino. Comentario sobre las Isagogae de Yoanicio. Liber Pronosticorum de Hipócrates. Libro Sobre Genética de Aureliano de Sica. Libro a Cleopatra sobre Genética. Libro de Musción Sobre las pesas. Síntesis médica en un volumen.

CCXII. Constantino: Toda la Medicina de Constantino, es decir, todo el saber sobre Medicina.

CCXIII. Constantino: Síntesis médica, es decir, Ars Minor.

CCXIV. Constantino: Viático de Constantino sobre Medicina, traducido del árabe al latín por él mismo.

CCXV. Alejandro: Sobre Medicina.

CCXVI. Yoanicio: Las Isagogae de Yoanicio sobre la técnica de Galeno. Aforismos de Hipócrates. Liber Pronosticorum. Libro sobre el pulso y la orina, en un volumen.

CCXVII. Glosas sobre los anteriores en quince libros.

CCXVIII. Dietas particulares de medicina.

CCXIX. Dietas generales de medicina.

CCXX. Libro de los grados (de fiebre), con el libro áureo de medicina.

CCXXI. Los Antídotos médicos. Sigue la anotación de los libros que se añadieron antes a la Biblioteca de Saint Amand, bajo mis cuidados, que quise se hiciera la presente anotación, para tener a Dios propicio en las piadosas oraciones de los hermanos que las leyesen.

CCXXII. El Génesis comentado.

CCXXIII. Libro de los pensamientos sobre el Génesis, recogidos de libros de muy numerosos doctores.

CCXXIV. El Éxodo comentado. 
CCXXV. Selecciones de libros de Gregorio sobre el Génesis y el Éxodo.

CCXXVI. El Levítico comentado.

CCXXVII. El Numerus comentado.

CCXXVIII. El Deuteronomio comentado.

CCXXIX. Radulfo: Sobre el Levítico.

CCXXX. Isaías comentado.

CCXXXI. Los doce Profetas comentados.

CCXXXII. De nuevo los doce Profetas comentados.

CCXXXIII. Lamentaciones de Jeremías comentadas, y el Cantar de los Cantares glosados con las opiniones de algunos doctores.

CCXXXIV. El Salterio glosado.

CCXXXV. Ofrido: Glosas sobre los títulos de los Salmos, con glosas del maestro Ofrido sobre algunos versos de algunos Salmos.

CCXXXVI. Albrico: Glosas del maestro Albrico sobre el Salterio.

CCXXXVII. Gilberto: Glosas del maestro Gilberto sobre el Salterio.

CCXXXVIII. Glosas de cierto maestro sobre el Salterio.

CCXXXIX. Glosas sobre el Salterio, seleccionadas por alguno de nuestros hermanos, en tres volúmenes.

CCXL. Salterio en cuatro partes, a saber, Francés, Latín, Hebreo, Griego, y el Breviario Menor de Jerónimo, con las Cartas del mismo sobre el Salterio, y las Sentencias de ciertos doctores, con Notas sobre Mateo, en un volumen.

CCXLI. Mateo comentado.

CCXLII. Glosas seguidas sobre Mateo, según la lectura del maestro Anselmo.

CCXLIII. Juan comentado.

CCXLIV. Zacarías de Crisa: Sobre el consenso de los Evangelistas.

CCXLV. Cartas de Pablo comentadas, en dos volúmenes.

CCXLVI. Gilberto: Glosas del maestro Gilberto sobre las Erpístolas de Pablo, en dos volúmenes.

CCXLVII. Séneca: Epístolas de Séneca a Pablo el Apóstol y a Lucilio, con los libros Sobre los beneficios del mismo autor Siue de Liberalitate. A Eburtio. De clementia ad Neronem. De copia uerborum a Pablo el Apóstol; Los Proverbios del mismo autor ordenados alfabéticamente; el libro Sobre los remedios de las desdichas, en un volumen.

CCXLVIII. Orígenes: Homilías sobre Heptático; Sobre Samuel; Sobre Isaías; Sobre el Cantar de los Cantares, en dos volúmenes.

CCXLIX. Cipriano: Sobre la oración dominical, y De símbolo.

CCL. Jerónimo: Sobre Isaías, en dos volúmenes.

CCLI. Jerónimo: Sobre Marcos; Sobre las Epístolas de Pablo a los Gálatas, a los Efesios, a Tito, a Filemón; el Contra Rufino.

CCLII. Jerónimo: Cartas en dos volúmenes; en el segundo se contienen libros del mismo autor: Sobre Daniel, Cuestiones Hebraicas, De los nombres Hebreos, De los lugares y el De Viris Illustribus.

CCLIII. Jerónimo: La Crónica. Siguen luego la Crónica de Próspero y la de Sigberto.

CCLIV. Viejo y Nuevo Testamento en cinco volúmenes, que se leían en el comedor.

CCLV. De nuevo Viejo y Nuevo Testamento en dos volúmenes en letra minúscula. (Éstos los llevaba consigo el venerable Abad Hugo II; él los mandó anotar brevemente, 
para que tengan, dijo, mis venideros, donde fijar su atención, si quisieran, mientras cabalgan y se envuelven en los asuntos del mundo).

CCLVI. Graciano.

CCLVII. Cuerpo de Cánones.

CCLVIII. Libro Episcopal, también llamado Ordinarius.

CCLIX. Libro de los Evangelios reunido en uno a partir de los cuatro.

CCLX. Plinio.

CCLXI. Agustín: Retractationes. Libro sobre los Académicos. Sobre la vida feliz. Sobre el orden de las cosas. Soliloquios. Sobre la inmortalidad del alma. Sobre las costumbres de la Iglesia Católica. Sobre las costumbres de los Maniqueos. Contra la epístola de los Maniqueos, a la que llaman de la fundación, en un volumen.

CCLXII. Agustín: Sobre la esencia del alma. Sobre la Naturaleza y la Gracia. Sobre la predestinación de los Santos. Sobre el bien de la perseverancia. Sobre el matrimonio y la concupiscencia. Sobre la perfección de la justicia humana. Sobre la catequesis a los necios. Cuestiones de los Evangelios. En un volumen.

CCLXIII. Agustín: Sobre el Génesis. Contra los Maniqueos. Contra cinco heréticos. Sobre el combate cristiano. Enquiridion. Sobre los pastores. Sobre la mentira. Cuestiones sobre el Evangelio según S. Mateo. En un volumen.

CCLXIV. Agustín: Sobre la Trinidad.

CCLXV. Agustín: Contra Fausto. Contra Adimanto, discípulo de un maniqueo. Contribución contra los Donatistas. Sermones. En un volumen.

CCLXVI. Agustín: Ochenta quejas de Agustín, en tres volúmenes.

CCLXVII. Agustín: Sobre la santa virginidad. Sobre la viudez santa. Sobre la fe o su símbolo. La Fides de S. León Papa, interpuesto delante el Sobre el Eclesiastés de Alcuino.

CCLXVIII. Agustín: Sobre la naturaleza del Bien. Sobre la utilidad del creer. Sobre el estilo del Nuevo Testamento. Enquiridion. Sobre la religión verdadera. Sobre el consenso de los Evangelistas. Sobre la primera Epístola de Juan. Sobre las diez cuerdas de un instrumento musical. Sobre la oración dominical. Sobre la fe o su símbolo. En un volumen.

CCLXIX. Agustín: Cuestiones sobre Eptático. Las ochenta quejas de Agustín. En tres volúmenes.

CCLXX. Agustín: Sobre las palabras del Señor y sobre las palabras del Apóstol.

CCLXXI. Agustín: Epistolario en dos volúmenes; en el segundo están libros del mismo autor: Sobre el bautismo de los niños, Sobre el espíritu y la letra, Contra el enemigo de la ley los profetas.

CCLXXII. Agustín: La Ciudad de Dios, en dos volúmenes. Los poemas de Ildeberto sobre las peculiaridades de las rocas; en el segundo están los siete libros de Agustín Sobre el bautismo, Sobre la Gracia y el libre albedrío, Contra las cinco clases de enemigos.

CCLXXIII. Agustín: Contra Juliano sobre la fe y las obras. A Polentio sobre las esposas adúlteras. Anotaciones a Job. Sermón sobre el sentido de las diez plagas con su decálogo.

CCLXXIV. Agustín: Contra Cresconio. Sobre las dos almas. Contra el maniqueo Fortunato. Contra el maniqueo Félix. Contra Pelagio y Celestio. Respuesta a Orosio so- 
bre los Priscilianistas. Sobre la mentira. Contra el engaño. Sobre el trabajo de los monjes. Versos de Gilberto sobre los milagros de San Amando.

CCLXXV. Agustín: Sobre el Génesis su documento. Sobre el Génesis contra los Maniqueos. Del combate cristiano. Sobre la divinidad de los daimones. Sobre los Pastores. Cuatro Sermones.

CCLXXVI. Agustín: Contra Maximino. Sobre Música.

CCLXXVII. Agustín: Sobre el Evangelio de S. Juan.

CCLXXVIII. Cipriano: Tratado de las cinco palabras del Señor en la Cruz. Epístolas. CCLXXIX. Libro Registro.

CCLXXX. Gregorio: Los Moralia en tres volúmenes.

CCLXXXI. Gregorio: Diálogos, junto con el Liber Pronosticorum.

CCLXXXII. Gregorio: Vida de S. Gregorio, con la Pastoral. Vida de S. Nicolás con el Traslado de su cuerpo y la Pasión de la virgen Santa Fe en verso.

CCLXXXIII. Isidoro: Etimologías.

CCLXXXIV. Beda: Sobre Lucas y sobre Marcos.

CCLXXXV. Beda: Sobre las parábolas de Salomón, con el sermón de Agustín sobre la mujer fuerte.

CCLXXXVI. Beda: Sobre el tabernáculo de Moisés. Sobre el templo de Salomón. Cuestiones sobre el libro de los Reyes con su explicación sobre Tobías.

CCLXXXVII. Beda: Antología, en dos volúmenes; en la segunda parte algo de las Cartas de Agustín.

CCLXXXVIII. Milagros de S. Esteban con la Pasión y milagros de Santos Cirico y Julita.

CCXC. Vida de S. Juan el Limosnero y de las Santas Paula, María Egipcíaca y la virgen Gertrudis.

CCXCI. Vitae Patrum.

CCXCII. Vidas de los Santos Anselmo, obispo de Canterbury y del Abad Agilo.

CCXCIII. Anselmo: Meditaciones.

CCXCIV. De nuevo Vida de San Amando y la Pasión de S. Cirico igualmente renovada con antiguos milagros del mismo padre y con el descubrimiento de su cuerpo.

CCXCV. Estas mismas cosas se contienen en otro volumen; los capítulos de este libro están ornados con letras de oro; se añadió la Pasión y la Inventio del protomártir Esteban.

CCXCVI. Ivo, obispo de Chrartres: Sobre los Sacramentos. Y versos de Hildeberto, obispo de Le Mans, sobre el misterio de la Misa; sigue la Disputa de un cristiano y un judío, así como la Institutio de disciplina regular

CCXCVII. Ivo: Los Decretos de Ivo.

CCXCVIII. Ivo: Las Cartas de Ivo.

CCIC. Hugo: Libro primero del maestro Hugo sobre los Sacramentos del Viejo Testamento.

CCC. Hugo: Libro segundo del autor anterior sobre los Sacramentos del Viejo Testamento.

CCCI. Hugo: Volumen que contiene los mismos dos libros anteriores, con opiniones del mismo Hugo sobre algunos versos del Salterio y con el tratado del mismo autor Sobre el alma de Cristo. 
CCCII. Hugo: Diálogo del maestro Hugo, con su tratado sobre el Eclesiastés.

CCCIII. Hugo. Didascalicon del maestro Hugo y Tratado sobre las lamentaciones de Jeremías con opiniones de un discípulo suyo sobre los Sacramentos.

CCCIV. Hugo: Notas del maestro Hugo sobre el Prólogo de Desiderio y sobre los libros del Génesis, Éxodo, Levítico, los Jueces y los Reyes.

CCCV. Hugo: Crónica del maestro Hugo.

CCCVI. Roberto: Sobre los Oficios Divinos, con su libro sobre los Sacramentos; al fin del libro el poema de Hildeberto sobre María Magdalena, Inés y Susana.

CCCVII. Bernardo: Sermón del Venerable Abad Bernardo sobre el Cantar de los Cantares.

CCCVIII. Bernardo: el Liber sobre el libre arbitrio.

CCCIX. Bernardo: el Liber Apologeticus.

CCCX. Bernardo: Tratado sobre el amor a Dios, con el tratado del maestro Gualterio Sobre el Matrimonio.

CCCXI. Sermón del Señor del Abad Enrique.

CCCXII. Pasión de San Jorge.

CCCXIII. Angelomo: Sobre los cuatro libros de los Reyes, y algunas Sentencias de Rábano.

CCCXIV. Sermones sobre las sentencias de los libros divinos, el primero de los cuales: No temas, hija de Sion; con selecciones de los libros del dichoso Gregorio sobre el Cantar de los Cantares.

CCCXV. Historia de cómo fue atacada Jerusalén por los cristianos, en el año del Señor de 1098, y descripción de los lugares de los alrededores de aquella, con la descripción de la magnificencia de la iglesia Romana, y con otros opúsculos. 